\title{
A Cúpula Mundial sobre o Desenvolvimento Social e os paradoxos de Copenhague*
}

\author{
J.A. LINDGRENALVES**
}

\section{A rationale e a mobilização da Cúpula}

A Cúpula Mundial realizada em Copenhague de 6 a 12 de março de 1995, diferentemente das demais conferências da agenda social da ONU na década de 90, não teve precedentes. Foi o primeiro grande encontro internacional havido sobre o tema do desenvolvimento social. Esse fato é consignado no primeiro parágrafo preambular da Declaração político-programática solenemente adotada na ocasião pelos governantes presentes ou representados na capital dinamarquesa, nos seguintes termos: "Pela primeira vez na história, a convite das Nações Unidas, nós, Chefes de Estado e de Governo, reunimo-nos para reconhecer a importância do desenvolvimento social e do bem-estar humano de todos, e para conferir a esses objetivos a mais alta prioridade, agora e no Século XXI”. ${ }^{1}$

A qualquer observador da história dos tempos modernos pode afigurar-se paradoxal que a primeira conferência multilateral de grande magnitude sobre o tema do desenvolvimento social se tenha realizado precisamente numa época em que o neoliberalismo, como alternativa "eficiente" ao chamado Estado-Providência, e o culto do mercado, como fator de regulação “natural” da convivência social, configuram a ideologia dominante em escala planetária.

Esse paradoxo é real, mas só se tornou efetivo um ano e meio depois do lançamento da idéia da Cúpula, pelo Chile, em 1991, no âmbito do Conselho

Rev. Bras. Polít. Int. 40 (1): 142-166 [1997].

* O presente texto é capítulo de livro em elaboração sobre o conjunto de conferências da ONU da década de 90. Apresenta percepções e opiniões pessoais de autor, não devendo ser confundido com posições do Governo brasileiro.

** Diplomata. Foi delegado à Cúpula Mundial sobre o Desenvolvimento Social e exerceu a função de Secretário Executivo do Comitê Nacional preparatório para o evento. 
Econômico e Social da ONU, quando de seu endosso consensual pela Assembléia Geral em 1992, acentuando-se no desenrolar do processo preparatório para o evento. Nos compromissos e propostas de ação adotados em Copenhague, em 1995, tal paradoxo se configurará de forma apenas parcial, enquanto outros tipos de contradições se tornarão evidentes.

Oprimeiroparadoxoarespeito daCúpulaMundial sobreo Desenvolvimento Social reside no fato de a proposta de sua realização ter sido aceita mais rapidamente pelos países desenvolvidos do que pelo conjunto de países em desenvolvimento. E ele tem explicação.

Por mais sérias que fossem as preocupações com a matéria e as motivações dos iniciadores da proposta, as resistências encontradas entre alguns países em desenvolvimento, na fase imediatamente posterior ao fim da Guerra Fria, tinham sua razão de ser. O triunfalismo do Ocidente desenvolvido com o esboroamento do antigo bloco comunista e a alegada vitória do liberalismo sobre o “socialismo real” e o centralismo burocrático estatista traduzia-se, então, não apenas na noção da “nova ordem internacional” preconizada pelo Presidente Bush dentro do Grupo dos Sete (“clube” dos países mais ricos) - encarada de forma tanto mais ameaçadora pelo resto do mundo porquanto associada à disseminação concomitante de novos conceitos dúbios, como o do "direito de ingerência". 2 Refletia-se tambémna insistência com que alguns países desenvolvidos brandiam a noção de good governance, ou "boa governança”, na qual se embutia uma crítica dirigida aos países do Terceiro Mundo como locus exclusivo do desperdício de recursos e da corrupção governamental - antes, naturalmente, da Operação Mãos Limpas na Itália, que virou de ponta-cabeça o sistema político vigente no país, e da divulgação deescândalos de corrupção mais individualizados envolvendo governantes de vários outros países desenvolvidos. Temiam, assim, os representantes de países em desenvolvimento, na ONU, que a conferência proposta se transformasse num foro de repreensão no sentido Norte-Sul, em que os países ricos viessem a tentar impor novos tipos de condicionalidades à assistência eà cooperaçãointernacionais.

Foi necessário, nessas condições, que o Representante Permanente do Chile junto às Nações Unidas, Embaixador Juan Somavía, na qualidade de representante especial do Secretário Geral para esse fim, desenvolvesse consultas sobre a matéria ao longo de mais de um ano, para que a Assembléia Geral tomasse a decisão de convocar o encontro mundial, em nível de Chefes de Estado e de Governo, em Copenhague, em 1995. Fê-lo, então, de forma muito positiva, pela Resolução 47/92, de 16 de dezembro de 1992, declarando-se “convencida da necessidade de aprimoramento do componente social do 
desenvolvimento sustentável para que se alcance o crescimento econômico com justiça social, (...) cônscia da necessidade de se estabelecerem meios e modos para a eliminação da pobreza disseminada e para o pleno desfrute dos direitos humanos, que incluem os direitos civis, políticos, econômicos, sociais e culturais, como objetivos inter-relacionados", e assinalando que "a pobreza, o desemprego e a integração social encontram-se interligados em todas as sociedades, com impacto particularmente profundo nos países em desenvolvimento”. ${ }^{3}$

O conceito de “desenvolvimento social” é algo que não constava originalmente da Carta das Nações Unidas. Emergira, aos poucos, na década de 60, quando a questão do desenvolvimento, na esteira do processo de descolonização, passara a ocupar o centro das atenções internacionais. Nunca fora, porém, definido com clareza. Envolvia basicamente a adição, às vezes sucessiva, outras vezes cumulativa, de setores como os da educação, da saúde, do trabalho, da moradia, dos serviços sociais e da previdência social à avaliação do funcionamento geral das sociedades. Como os três primeiros elementos-a educação, a saúde e o trabalho - já eram tratados por organizações especializadas do sistema - a Organização das Nações Unidas para a Educação, a Ciência e a Cultura(UNESCO), a Organização Mundial da Saúde(OMS) e a Organização Internacional do Trabalho(OIT)-, o Conselho Econômico e Social (ECOSOC) sempre tendeu a abordar o tema de forma fragmentada, focalizando a situação de setores específicos, ou por meio de estudos genéricos da situação mundial que levavam em conta indicadores econômicos, como a renda per capita ou a expectativa de vida nos diversos países. Apresentava-se, assim, nitidamente subordinado às questões mais estritamente econômicas. ${ }^{4}$ Em função desses fatos, não era de surpreender que a Comissão para o Desenvolvimento Social das Nações Unidas, estabelecida em 1966 para orientar o ECOSOC a respeito de políticas sociais, sempre constituísse uma espécie de foro "de segunda classe” por comparação com as demais comissões funcionais do Conselho (como, inter alia, a Comissão dos Direitos Humanos e a Comissão sobre a Situação da Mulher): contava e ainda conta com menor número de membros; desde 1971, suas sessões passaram de anuais a bienais; as resoluções e recomendações dela emanadas eram examinadas de maneira perfunctória pelos órgãos superiores.

O súbito interesse internacional pelo tema do desenvolvimento social nos anos 90, conforme afinal definido pela Resolução 47/92, no processo preparatório para a Cúpula Mundial e na movimentação planetária que ela provocou, evidencia, pelo menos, que o chamado "consenso neoliberal” do mundo contemporâneo não étão consensual quanto parece. Embora predominante 
nos setores político-econômicos que detêm o poder em quase todo o planeta, a obsessão com o monetarismo, a liberdade do mercado e o "Estado mínimo” é, ao contrário, motivo de sérias preocupações, tanto nos países em desenvolvimento - maioria numericamente esmagadora na composição da Assembléia Geral da ONU-, como nas sociedades civis dos países desenvolvidos. E seus opositores, governamentais e não-governamentais, conquanto não dispondo de meios suficientes para revertê-la, têm capacidade para mobilizar a opinião pública internacional em campanhas de conscientização de vasto espectro, assim como para implementar iniciativas localizadas importantes com o objetivo de obviar alguns de seus efeitos mais daninhos.

Entre os diversos objetivos fixados para a Cúpula Mundial na Resolução 47/92 relacionavam-se os de:

“(e) criar uma consciência internacional e definir modalidades de ação para se atingir o equilíbrio necessário entre a eficiência econômica e a justiça social, num ambiente de desenvolvimento equânime e sustentável, voltado para o crescimento, de acordo com prioridades definidas no âmbito nacional;

(f) tratar, de maneira criativa, da interação entre a função social do Estado, as respostas do mercado às demandas sociais e os imperativos do desenvolvimento sustentável;

(g) identificar os problemas comuns dos grupos socialmente prejudicados e marginalizados e promover sua integração na sociedade, salientando-se a necessidade de as sociedades igualizarem as oportunidades para todos os seus membros; ...”

Tendo em mente esses e outros objetivos - elencados de (a) a (k) na Resolução 47/92 -, os três principais temas "que afetam todas as sociedades" selecionados para exame na Cúpula seriam: a integração social dos grupos mais prejudicados e marginalizados, o alívio e a redução da pobreza e a expansão do emprego produtivo.

Para o encaminhamento das discussões e a preparação dos documentos a serem considerados em Copenhague, a Assembléia Geral estabeleceu um Comitê Preparatório - que se reuniu em sessões formais e informais de abril de 1993 a janeiro de 1995 - aberto a todos os Estados-membros das Nações Unidas, representados por delegados especialmente designados para esse fim pelos respectivos Chefes de Estado e de Governo, bem como às agências internacionais. A antes negligenciada Comissão para o Desenvolvimento Social foi instruída a realizar sessão extraordinária-que atraiu afluência einteresse inéditos de governos e ONGs - para tratar da Cúpula, em 1993. As Comissões regionais 
da ONU, entre as quais a CEPAL, receberam recomendações no sentido de preparar relatórios integrados com vistas à realização do encontro. E todas as agências especializadas do sistema da ONU e de Bretton Woods - o FMI e o Banco Mundial-foram mobilizadas para o evento.

A exemplo das demais conferências da década de 90, o encontro de Copenhague desenvolveu-se em diversos planos. Inaugurado em nível de delegações oficiais negociadoras, estendeu-se, com o formato de grande conferência - com 186 Estados e organizações de integração regional participantes - de 6 a 10 de março de 1995, desdobrado em um Plenário, um Comitê Plenário negociador e vários grupos de negociação para subtemas específicos, reunidos em sessões paralelas a seminários, palestras e conferências de especialistas e de agências das Nações Unidas. A ela se seguiu a Cúpula propriamente dita, nos dias 11 e 12 de março, da qual participaram 117 Chefes de Estado e de Governo - recorde que ultrapassou os 105 da "Cúpula da Terra" na RIO-92 - e altos representantes de outros países, que proferiram um total de 232 alocuções e adotaram os documentos previamente aprovados pela conferência negociadora. Ao todo, a Cúpula Mundial sobre o Desenvolvimento Social congregou no Bella Centre de Copenhague 14.200 pessoas, das quais 5.000 delegados oficiais, mais de 2.800 jornalistas e funcionários de agências de comunicação, 2.300 representantes de organizaçõesnão-governamentais (ONGs), 2.700 funcionários locais e agentes de segurança e 400 membros do Secretariado das Nações Unidas e de suas agências. Em paralelo aos eventos oficiais, um Fórum de ONGs, reunido de 3 a 12 de março em outra ilha da capital dinamarquesa - a ilha de Holmen -, com 4.500 participantes vindos do exterior, realizou cerca de 1.500 encontros, mais de 100 atividades culturais e 400 exposições. $^{5}$

Nas palavras com que o então Secretário Geral das Nações Unidas, Boutros Boutros-Ghali, abriu os trabalhos no dia 6 de março, a Cúpula era apresentada comouma tentativa de renovação do projeto progressista do Iluminismo: "Um novo contrato social, de nível global, é preciso para trazer esperança aos Estados e nações, aos homens e mulheres de todo o mundo. Esse deve ser o foco da Cúpula Mundial. Assim entendo eu como ela deve ser vista”. ${ }^{6}$

\section{A paz e os objetivos do desenvolvimento}

Independentemente dos méritos e deméritos dos documentos aprovados em Copenhague, a simples realização do encontro, com a mobilização que ele propiciou, envolvendo atores governamentais e não-governamentais - embora 
a ausência do setor empresarial tenha sido notória - já teria ipso facto o mérito de trazer, pela primeira vez, o desenvolvimento social à linha de frente das atenções internacionais. E essas atenções, num mundo cada vez mais globalizado pela economia e pelas comunicações, mas assolado pelo desemprego e pela exclusão social, com acréscimo de tensões difusas e guerras intestinas, justificamse até mesmo pela ótica do primeiro propósito das Nações Unidas, estabelecido no Artigo $1^{\circ}$, parágrafo $1^{\circ}$, de sua Carta constitutiva: o da manutenção da paz e da segurança internacionais. Esse fato torna-se evidente na Declaração adotada pelos Chefes de Estado e de Governo, que aperfeiçoa e explicita a interligação da paz e da segurança internacionais com o desenvolvimento econômico-social, a justiça e os direitos humanos, já reconhecida no preâmbulo da Carta da ONU desde 1945.

No preâmbulo da Declaração de Copenhague, os Presidentes e Primeiros Ministros da quase totalidade dos países do mundo afirmam: “Compartilhamos a convicção de que o desenvolvimento social e a justiça social são indispensáveis para a consecução e a manutenção da paz e da segurança dentro de nossas nações e entre elas. Por outro lado, o desenvolvimento social e a justiça social não podem ser alcançados se não houver paz e segurança ou se não forem respeitados todos os direitos humanos e liberdades fundamentais. Essa interdependência essencial foi reconhecida há 50 anos na Carta das Nações Unidas e desde então se tem tornado cada vez mais profunda” (quinto parágrafo).

A essa explicitação o mesmo documento oferece maior consistência, ao reconhecer que: “... nossas sociedades precisam responder mais eficazmente às necessidades materiais e espirituais dos indivíduos, de suas famílias e das comunidades em que vivem nos diversos países e regiões" (terceiro parágrafo do preâmbulo); e ao reiterar a asserção da RIO-92 de que: "as pessoas são o centro de nossas preocupações com o desenvolvimento sustentável e têm direito a uma vida saudável e produtiva, em harmonia com o meio ambiente (oitavo parágrafopreambular). ${ }^{7}$

Se levarmos em conta que, nas décadas anteriores, as atenções dos encontros multilaterais sobre a questão do desenvolvimento, envolvendo países do Sul e do Norte, eram voltadas quase que exclusivamente para a idéia do crescimento econômico dos Estados, sem autocontroles racionais ou orientação axiológica, o progresso no sentido humanístico - já presente nos documentos da Conferência do Rio de Janeiro - oferecido pela Declaração de Copenhague é evidente. Por mais justificáveis que fossem as postulações dos países em desenvolvimento perante o Primeiro Mundo nos anos 60 a 80 em favor de uma Nova Ordem Econômica Internacional, elas se ressentiam da 
falta de uma definição adequada sobre a finalidade do desenvolvimento - para não falar de seu enquadramento jurídico ou de sua titularidade como um direito (o direito ao desenvolvimento), esboçados agora, particularmente desde a Conferência de Viena de 1993 sobre direitos humanos, de forma muito incipiente.

Conforme é hoje amplamente reconhecido, o desenvolvimento como sinônimo de industrialização e crescimento econômico não produz por si só o aprimoramento necessário das condições sociais. Pode, até, ao contrário, como tem sido comprovado nos relatórios anuais do PNUD, agravar os desequilíbrios inter e intra-estatais, através do aumento da concentração de riquezas nos setores sociais privilegiados, com a conseqüente deterioração da vida de vastas camadas populacionais, envolvidas no êxodo rural e pauperizadas nos centros urbanos. Isso em paralelo a fenômenos diversos ligados à noção de desenvolvimento econômico, como a substituição de culturas de subsistência por monoculturas de exportação, com efeitos perniciosos à alimentação e subsistência das populações agrárias, a reorientação do investimento de cunho social, na educação, saúde, trabalho e segurança para obras de infra-estrutura que apenas beneficiam a própria indústria ou as culturas de exportação, e muitas outras manifestações socialmente negativas sobejamente conhecidas e onipresentes.

Nas palavras de Átila Roque, do IBASE, que acompanhou o processo preparatório da Cúpula e a delegação do Brasil ao evento, o encontro de Copenhague "foi uma tentativa de superar o estado de descaso e quase cinismo com quea comunidadeinternacional pensava a problemática do desenvolvimento”. A Cúpula teria respondido a esse descaso porque reintroduziu, no cenário internacional, "uma discussão que esteve muito em pauta na década de 70, sobre os objetivos últimos do desenvolvimento. É muito importante ver as Nações Unidas reavaliarem o lugar do desenvolvimento na aventura humana". ${ }^{8}$

Se, sob certos aspectos, e para as aspirações mais otimistas, a Cúpula Mundial pode ter sido frustrante, é inegável que, malgrado as limitações, seus documentos finais - a "Declaração de Copenhague sobre o Desenvolvimento Social” e o "Programa de Ação da Cúpula Mundial sobre o Desenvolvimento Social”-trazem importantes contribuições ao tratamento nacional e internacional de seu megatema, a que se subordinam, direta ou indiretamente, todos os demais assuntos da agenda social da ONU. Exatamente porque o tema era muito abrangente, torna-se difícil identificar de maneira objetiva o foco principal das decisões de Copenhague. Ressalta, porém, em ambos os documentos, a determinação declarada de se encarar e promover o desenvolvimento não como 
um fim em si, mas como um meio para o aperfeiçoamento da vida humana, tendo por base o respeito e a implementação de todos os direitos fundamentais. Ressalta, também, seu caráter participativo, de convocação a todas as entidades e atores das sociedades civis para a realização dos esforços necessários à consecução dos objetivos colimados.

A expressão “desenvolvimento social”, de conceituação imprecisa como, de resto, quase todos os grandes temas da atualidade-, passa, portanto, a ter agora um sentido claramente humanista, consensualmente definido. É ele que fundamenta o conceito de desenvolvimento, já previamente qualificado pela RIO-92 como necessariamente sustentável. E o desenvolvimento social, mais do que uma aspiração natural das sociedades, torna-se também fator imprescindível à consecução e à manutenção da paz intra e internacional, da qual é simultaneamente dependente, assim como o é da realização dos direitos humanos universais.

\section{Os compromissos e as frustrações de Copenhague}

De maneira simplificada, é possível sumariar as conquistas dos documentos finais de Copenhague nas seguintes promessas coletivas, constantes dos 10 compromissos que conformam a Declaração dos Chefes de Estado e de Governo:

1-decriar um ambiente econômico, político, social, cultural e jurídico que permita o desenvolvimento social das pessoas;

2 - de erradicar a pobreza no mundo, por meio de ação nacional enérgica - com enfoque multidimensional e integrado, em cooperação com todos os membros da sociedade civil-e da cooperação internacional, como um imperativo ético, social, político e econômico da humanidade;

3-depromover o pleno emprego e de capacitar os homens e as mulheres a conseguirem meios de vida seguros e sustentáveis;

4 - de promover a integração social fomentando sociedades estáveis, seguras e justas, baseadas em todos os direitos humanos;

5 - de promover o pleno respeito à dignidade humana, de alcançar a igualdade e a eqüidade entre homens e mulheres, de reconhecer e aumentar a participação e as funções de liderança da mulher na vida política, civil, econômica, social e cultural e no desenvolvimento; 
6 - de promover o acesso universal e eqüitativo a uma educação de qualidade e ao nível mais alto possível de saúde física e mental, assim como o acesso de todas as pessoas à assistência básica de saúde, procurando especialmente retificar desigualdades sociais sem distinções de raça, origem nacional, sexo, idade ou deficiência, respeitando as culturas comuns e particulares, preservando as bases do desenvolvimento sustentável centrado nas pessoas, contribuindo para o pleno desenvolvimento dos recursos humanos e para o desenvolvimento social. “A finalidade destas atividades é de erradicar a pobreza, promover o emprego pleno e produtivo e fomentar a integração social”. ${ }^{9}$

7-de acelerar o desenvolvimento econômico, social e humano da África e dos países de menor desenvolvimento (“LDCs”);

8-de assegurar que os programas de ajuste estrutural incluam objetivos de desenvolvimento e integração social;

9 - de aumentar substancialmente ou utilizar com maior eficácia os recursos destinados ao desenvolvimento social;

10 - de melhorar e fortalecer o quadro da cooperação internacional, regional e sub-regional para o desenvolvimento social, em espírito de parceria, através das Nações Unidas e outras instituições multilaterais. ${ }^{10}$

Os dez compromissos são respaldados por um Programa deAção, em que se delineiam, em mais de uma centena de páginas, políticas e medidas destinadas a promover a integração social em áreas que envolvem a forma de atuação dos Governos, a não-discriminação, a igualdade e a justiça social, as necessidades particulares dos indivíduos e grupos mais vulneráveis, as necessidades especiais dos migrantes e refugiados, a violência e o crime e o papel da família. De maneira bastante objetiva, concentrado apenas nas proposições de conteúdo prático, o mais breve resumo do "Programa deAção da Cúpula Mundial sobre o Desenvolvimento Social”, feito pelo Departamento de Informação Pública das Nações Unidas, sumaria o documento como um conjunto de "recomendações para eliminar as desigualdades dentro dos países e entre eles (...), as quais incluem:

- um chamamento ao Banco Mundial, ao FMI e a outras instituições de financiamento para que tornem o desenvolvimento social o principal foco de suas políticas, especialmente nos programas de ajustamento estrutural;

- apoio à fórmula das Nações Unidas segundo a qual cada país doador destinaria $20 \%$ de seus fundos de assistência ao exterior a objetivos de desenvolvimento social, tais como alimentação, saúde, água potável e educação, enquanto os países em desenvolvimento devotariam $20 \%$ de seus orçamentos nacionais aos mesmos objetivos (a chamada “fórmula 20/20”); 
- chamamentos para oalívio da dívida externa-inclusive seu cancelamento total-a fim de auxiliar os países em desenvolvimento com dificuldades financeiras a começarem a corrigir seus problemas sociais;

- promessas de estabelecimento de cronogramas para a eliminação da pobreza absoluta." 11

O simples enunciado dos compromissos da Declaração torna manifesta a importância atribuída pela Cúpula de Copenhague ao tema dos direitos humanos, com forte valorização dos conceitos de igualdade, eqüidade e não-discriminação, a exemplo do que já se observara na Conferência do Cairo sobre População e Desenvolvimento. Ademais da ênfase nos direitos humanos, comum a toda a agenda social da ONU na época atual, a Cúpula foi ainda mais claramente antropocêntrica do que a Conferência do Cairo: se os autores e primeiros destinatários dos documentos de Copenhague são os Estados, os compromissos assumidos por seus dirigentes não têm por beneficiários os Estados como entidades políticas, mas sim os seres humanos - nas dimensões individual e coletiva - que os integram, e que conformariam, no contexto planetário, uma verdadeira comunidade internacional.

Dentro da mesma lógica descentralizadora e desestatizante, que, aliás, vem sendo seguida em todas as conferências da década, os Estados, personificados em seus governantes, reconhecem ser deles a principal responsabilidade para o alcance dos objetivos propostos, mas reconhecem igualmente que as organizações internacionais eregionais bem como “todos os atores da sociedade civil” necessitam contribuir para os mesmos fins. Nessas condições, os governantes "convidam todas as pessoas a expressarem sua determinação de aprimorar a condição humana, por meio de ações concretas nas respectivas áreas de atividade ou da assunção de responsabilidades cívicas específicas” (parágrafo 27 do preâmbulo da Declaração). ${ }^{12}$

Levando em consideração que o desenvolvimento social tem como ingrediente fundamental o respeito e a implementação dos direitos humanos, a Declaração e o Programa de Ação de Copenhague apresentam incentivos genéricos e específicos à realização desses direitos. Nesta segunda categoria, de incentivos particularizados, enquadram-se os compromissos incidentes sobre, inter alia:

a) “a ratificação e a plena aplicação dos instrumentos pertinentes ... como o Pacto Internacional de Direitos Econômicos, Sociais e Culturais e o Pacto Internacional de Direitos Civis e Políticos” (primeiro compromisso, parágrafo 28, f, da Declaração); 
b) “a observância dos convênios pertinentes da Organização Internacional do Trabalho" para "proteger e fomentar o respeito aos direitos básicos dos trabalhadores, aí incluídos a proibição do trabalho forçado e do trabalho infantil, a liberdade de associação e o direito de organização e negociação coletiva e à não-discriminação no emprego" (compromisso 3, i, e parágrafo 54, b, do Programa de Ação);

c) a proteção "de todos os direitos humanos e liberdades fundamentais, que são universais, indivisíveis, interdependentes e inter-relacionados, inclusive o direito ao desenvolvimento...”, o "estabelecimento de mecanismos e recursos eficazes para assegurar seu cumprimento...” e a “criação e fortalecimento de instituições nacionais responsáveis por sua aplicação e vigilância” (parágrafo 15, b, do Programa de Ação);

d) a realização do direito ao desenvolvimento "mediante o fortalecimento da democracia, o desenvolvimento e o respeito aos direitos humanos eliberdades fundamentais...” (parágrafo 15, d, do Programa de Ação). ${ }^{13}$

A universalidade dos direitos humanos, consensualmente consagrada na Declaração de Viena de 1993, é, portanto, mais uma vez reiterada em Copenhague, assim como o são a inter-relação entre democracia, desenvolvimento e direitos humanos, o direito ao desenvolvimento em suas vertentes individual e coletiva, e todos os conceitos basilares das grandes conferências mundiais já então realizadas na década de 90 - inclusive os atinentes às questões de gênero, a serem observadas em todas as áreas sob consideração, à saúde reprodutiva e aos direitos a ela concernentes, consagrados na Conferência do Cairo.

Vistos por essa ótica, os documentos da Cúpula de Copenhague, ainda que não correspondam ao "novo contrato social de nível global” visualizado por Boutros-Ghali em seu discurso inaugural, ${ }^{14}$ aparecem extremamente positivos para o Homem e a Mulher, no sentido racional e subjetivista a eles atribuído pela modernidade iluminista, fixando valores supostamente universais por meio da ação comunicativa intercultural. O problema é que, como sempre tem ocorrido, a "modernidade" discursiva apresenta-se contraditória com a realidade do mundo. E a Cúpula sobre o Desenvolvimento Social não foi exceção. Aaltivez dos compromissos assumidos contrasta com a escassez de propostas concretas.

As frustrações amplamente verbalizadas sobre a Cúpula vinculam-se à falta de iniciativas capazes de promover a superação dos desequilíbrios internos e internacionais na distribuição da riqueza ou para apontar os meios de alcançála. A pouca criatividade, ou mais precisamente a ausência de vontade política, nessa área - resumida pelas ONGs presentes na expressão "promessas elevadas e bolsos vazios” ${ }^{15}$-, já lamentável em qualquer outro foro, foi tanto 
mais sentida numa conferência, de nível de Chefes de Estado e de Governo, que tinha como fundamentação particular a pobreza, o desemprego e a desintegração social. E é especialmente nesse campo, no estabelecimento de condições econômicas minimamente necessárias para o alcance da igualdade, mais do que nas inconsistências epistemológicas da razão ou nas imperfeições da afirmação da subjetividade, que o projeto da modernidade, tal como elaborado desde o "Século das Luzes”, tem fracassado tragicamente. Mais sensível no corpo da maioria dos indivíduos e comunidades do que todas as repressões disciplinares do poder ubíquo analisadas por Foucault na episteme moderna, é sobretudo esse fracasso que danifica, na escala mundial, a crença racional no progresso, prejudicando de maneira talvez irremediável os dois outros componentes da tríade da Revolução Francesa: liberdade e fraternidade.

Assim é que, na questão dos recursos para a implementação dos compromissos, o Programa de Ação de Copenhague apresenta-se extremamente conservador. A par da reiteração da chamada “fórmula 20/20" mencionada acima - que obteve algum impacto nos meios de comunicação, mas já fora recomendada pela ONU em documentos muito anteriores à Cúpula - e da recomendação, também antiga, aos países ricos de aumentarem os montantes destinados à ajuda externa e de "se esforçarem para destinar $0,7 \%$ dos produto nacional bruto à assistência oficial para o desenvolvimento” (parágrafo 87, letras “c” e "b" do Programa de Ação), ${ }^{16}$ pouco se aprovou. A proposta formulada pelo economista James Tobin desde 1978 e endossada pelo Relatório do PNUD sobre o Desenvolvimento Humano de 1994, no sentido da criação de um fundo de ajuda aos países em desenvolvimento com base em taxa de até 0,5\%, imposta internacionalmente, sobre as aplicações de capitais de curto prazo nos mercados monetários internacionais - estimadas em um trilhão de dólares por dia, sem qualquer efeito positivo na esfera produtiva ou na criação de empregos - foi muito aventada, mas não incorporada. Tampouco o foi a idéia, sugerida em Copenhague por muitos países, entre os quais o Brasil, de se promover uma revisão dos mecanismos e instituições financeiras multilaterais com vistas ao estabelecimento de um sistema eficaz de controle sobre os capitais financeiros especulativos - capitais estes cuja volatilidade fora experimentada amargamente pelo México pouco antes, na debandada maciça das vultosas quantias que haviam entrado no país em 1993, com o famigerado "efeito tequila" dela resultante.

No que diz respeito à oferta de meios e à definição de ações concretas para a implementação dos compromissos e do Programa de Ação da Cúpula Mundial sobre o Desenvolvimento Social, de pouco adiantou o fato de os governantes reconhecerem no preâmbulo da Declaração que: "Somente 
continuaremos a contar com a confiança das pessoas do mundo se fizermos de suas necessidades nossas prioridades. Sabemos que a pobreza, a falta de emprego produtivo e a desintegração social são uma ofensa à dignidade humana. Sabemos também que são fatores que se reforçam mutuamente, além de representarem uma perda de recursos humanos e uma manifestação de ineficiência no funcionamento de mercados e de instituições e processos econômicos e sociais". ${ }^{17}$

Na interpretação de Peter Townsend, a Cúpula de Copenhaguerepresentou uma "luta feroz" para se definir e lançar uma teoria e um programa alternativos para o desenvolvimento. Alguns participantes eram motivados pelas crescentes disparidades entre as nações ricas e pobres ou pela "hipocrisia da assistência externa”. Outros estariam descobrindo que os países ricos também tinham problemas sociais germinando em seus próprios quintais e, portanto, deveriam unir-se aos países pobres numa causa comum, para que tais problemas pudessem ser equacionados. A questão do desenvolvimento não poderia mais ser tratada como “uma teoria e um programa para os pobres”, mas para todos. Tal percepção, contudo, está longe de ser aceita no debate internacional. Na Cúpula de 1995, teria havido "muito pouco reconhecimento de que os piores problemas estruturais do mundo estão desestabilizando todos os países. E isso exige um enfoque completamentenovo". ${ }^{18}$

O indiferentismo do Primeiro Mundo com relação aos problemas dos países em desenvolvimento não chega a constituir novidade. O que semodificou na época presente foi a situação estrutural, em função das novas características da economia internacional, que vêm criando crescentes contingentes de marginalizados também dentro dos países mais desenvolvidos. Conforme ilustram os eloqüentes exemplos citados por Ignacy Sachs, a Espanha, entre 1980 e 1992, duplicou seu PIB sem criar um único emprego adicional, enquanto "num país tão rico como éa França, uma ruptura social separa hoje os dois terços de ganhadores do terço de perdedores, cada vez mais excluídos da sociedade de consumo e privados do exercício de seu direito-que, porém, é fundamental-ao trabalho". ${ }^{19}$

A globalização econômica, sem os corretivos necessários, associada ao desmantelamento deliberado do Estado de Bem-Estar, tende a globalizar também os problemas sociais do desemprego e da desintegração social (e com eles a criminalidade), tanto por fatores endógenos, como pelo inevitável incremento das migrações no sentido Sul-Norte. Diante desse fato evidente, cada dia mais sensível, o “integrismo” neoliberal dos países desenvolvidose dealgumas lideranças de países em desenvolvimento, manifestado em políticas domésticas e projetado na esfera internacional, inclusive na Cúpula de Copenhague, corresponde a uma forma de autismo, que, já vem sendo autodestrutivo. 
Se esse “integrismo” egocêntrico é autodestrutivo para as sociedades mais ricas, ele tende a ser catastrófico para o conjunto da humanidade. Segundo dados assinalados pelo Diretor Executivo do PNUD, James G. Speth, no Relatório sobre o Desenvolvimento Humano de 1994, nos últimos trinta anos a concentração de riqueza dentro dos países e entre eles simplesmente duplicou. Em 1962, a quinta parte mais rica da população mundial gozava de rendas 30 vezes superiores àquela de que dispunha a quinta parte mais pobre. Em $1994 \mathrm{a}$ disparidade da relação passara a ser de 60 a 1. E, em 1996, os 358 indivíduos bilionários existentes no mundo dispunham de uma renda combinada maior do que o Produto Interno Bruto somado de um conjunto de países que abriga 45\% da população mundial! ${ }^{20}$

\section{Os paradoxos do Grupo dos 77}

Se, por um lado, o “integrismo” neoliberal e o indiferentismo social por ele propiciado impediram a adoção de recomendações inovadoras para melhor distribuir a riqueza ou tornar mais factíveis os compromissos da Cúpula, por outro lado, os fundamentalismos religiosos, cada vez mais influentes nestes tempos denominados “pós-modernos”, quase provocaram retrocessos no que já se havia logrado estabelecer consensualmente na esfera de valores éticos e em matéria de direitos nas conferências anteriores.

Inconformados com os resultados das Conferências de Viena e do Cairo, especialmente esta última, os governos que haviam registrado reservas e declarações interpretativas aos respectivos documentos finais reabriram nas negociações de Copenhague todas as questões para eles duvidosas - como se os esforços de conciliação e acomodação dos eventos precedentes tivessem sido em vão e como se os documentos deles emergentes fossem letra morta. Mais uma vez os fundamentalistas de todos os credos procuraram fazer desaparecer dos textos as referências à saúde reprodutiva, aos meios de prevenção das doenças sexualmente transmissíveis, à família em suas diversas formas, à não-discriminação de gênero e à igualdade de direitos entre os sexos. Mais uma vez, ainda, a esdrúxula coalizão de teocracias historicamente antagônicas e governos laicos ditatoriais de direita e de esquerda tudo fez para inserir nos textos linguagem que relativizava os direitos humanos e reinstaurava o conceito absolutista de soberania como escudo a práticas domésticas inaceitáveis no direito internacional. ${ }^{21} \mathrm{E}$ a maior ameaça às conquistas conceituais das conferências anteriores adveio precisamente daquele agrupamento de países que mais deveria manter-se unido e consistente na luta contra a pobreza, 
ou, pelo menos, na luta para a obtenção de condições econômicas e assistência para a promoção do desenvolvimento social de suas populações: o Grupo dos 77.

Criado na década de 60 para coordenar as posições dos países em desenvolvimento em foros multilaterais na campanha por uma Nova Ordem Econômica Internacional, o Grupo dos 77 lograra, nas décadas passadas, disseminar a idéia, respaldada pelo bloco socialista, de que os problemas que enfrentavam na esfera do desenvolvimento eram decorrência exclusiva da estrutura injusta do sistema econômico internacional. Unia-o, pois, um lastro ideológico, inspirado na sociologia marxista, segundo o qual o ordenamento internacional capitalista, a exemplo das sociedades nacionais, dividia os Estados em classes, cabendo aos países subdesenvolvidos, na qualidade de proletariado de nações, a função emancipatória de revolucionar a ordem vigente para a construção de um mundo mais equânime. Justificada pela praxis da luta anticolonialista e antiimperialista, essa ideologia foi encampada não somente pelos setores de esquerda em todo o mundo, mas também por governos do Terceiro Mundo cuja ideologia e práticas domésticas eram a antítese do marxismo ou da própria social-democracia.

Com o presente descrédito da idéia de revolução e as enormes disparidades econômicas entre os países do Terceiro Mundo ainda mais aguçadas, diante da evidência, hoje em dia não dissimulada, de que as injustiças do ordenamento internacional refletem-se nas disparidades internas das sociedades dos próprios países em desenvolvimento e, sobretudo, pela obviedade do desejo de todos os Estados, do Norte e do Sul, independentemente dos respectivos sistemas políticos e culturais, de inserir-se sólida e vantajosamente na economia globalizada, o liame que unia o Grupo dos 77 praticamente desfez-se. Esse fato ficou patente em Copenhague até mesmo na ambigüidade e falta de convicção com que muitos integrantes do Grupo discutiram as sugestões concernentes ao alívio das dívidas externas dos países em desenvolvimento, já que vários deles são também credores de Estados mais pobres.

Desunidos na esfera econômica, os países do Grupo dos 77 têm procurado coordenar-se em outros campos para o enfrentamento diplomático multilateral com o Primeiro Mundo. Passam a assemelhar-se, assim, ao Movimento dos Não-Alinhados, essencialmente político, com o qual tende a confundir-se. O Movimento dos Não-Alinhados, por sua vez, ainda mais do que o Grupo dos 77, perdeu sua lógica com o fim da Guerra Fria.

Oriundo da Conferência de Bandung de 1955, foi sobretudo esse Movimento, de composição majoritariamente afro-asiática, que, nos anos 60 e 70, deu substância à noção de um Terceiro Mundo, capaz de oferecer a 
alternativa de uma "terceira via” à disputa hegemônica Leste-Oeste, polarizada por Washingtone Moscou, e ao conflito ideológico capitalismo versus comunismo. Em seu discurso inaugural na Conferência Afro-Asiática de 1955, o Presidente Sukarno, da Indonésia, justificava a criação de um movimento de países nãoalinhados com a afirmação de que: "Podemos mobilizar toda a força espiritual, moral e política da África e da Ásia no lado da paz... Bem mais do que metade da população humana do mundo, nós podemos mobilizar o que tenho chamado de 'Violência Moral das Nações' em favor da paz”. ${ }^{22}$

Por mais idealizada einobservada que tenha sido essa "terceira via” pelos membros do Movimento Não-Alinhado, ela poderia fazer sentido num mundo bipolar. Na estrutura multipolar presente, a superação da proposta do nãoalinhamento ficou logo tão evidente que, na primeira reunião ministerial do Movimento após a dissolução da União Soviética e o banimento do Partido Comunista da URSS, realizada em Accra, em 1991, vários países expressivos, entre os quais o Egito (fundador e articulador do não-alinhamento original), chegaram a propor-sem êxito - sua autodissolução e substituição pelo Grupo dos 77, cujos objetivos de coordenação em matéria econômica pareciam mais condizentes com a nova realidade.

Com a mensagem política alternativa esvaziada pelo fim da bipolaridade estratégica e o amálgama econômico enfraquecido pela globalização, um dos maiores problemas com que se defrontam os Estados do Sul nos foros multilaterais reside atualmente na falta de um cimento aglutinador e coerente. Disso se têm aproveitado os governos autoritários laicos e fundamentalistas religiosos, que manipulam tanto o Movimento Não-Alinhado como o Grupo dos 77 para a defesa de suas posturas antiliberais.

De todas as iniciativas antiliberais forçadas pela militância ditatorialfundamentalista em nome do Grupo dos 77, a última a ser contornada em Copenhague - graças em parte à atuação brasileira ${ }^{23}$ - simboliza de maneira eloqüente todas as demais.

Conforme tem sido prática nas grandes conferências, as negociações de Copenhague deveriam ater-se a buscar o consenso sobre pontos já examinados nas sessões do Comitê Preparatório ainda assinalados entre colchetes nos projetos em consideração. ${ }^{24}$

Quando as negociações já entravam na fase final, com poucos pontos pendentes nos grupos de trabalho, o Grupo dos 77 aprovou, em momento de ausência do Brasil e da maioria dos demais países latino-americanos, como proposta comum, um parágrafo novo para o chapeau dos compromissos a serem assumidos pela Cúpula, estabelecendo que “a formulação e a implementação de 
estratégias, políticas, programas e ações em favor do desenvolvimento social são de responsabilidade de cada país e devem levar em conta a diversidade econômica e social das respectivas condições, com pleno respeito aos diversos valores religiosos e éticos, contextos culturais e convicções filosóficas de seus povos”. Redigida apenas nesses termos, a proposta representaria um óbvio retrocesso à universalidade dos direitos humanos consensualmente confirmada pela Conferência de Viena de 1993 e uma revisão regressiva ao chapeau dos Princípios do Programa de Ação do Cairo, de 1994 - que reafirmava o respeito às soberanias e aos contextos e valores religiosos e culturais, mas "em conformidade com os direitos humanos internacionalmente reconhecidos". 25

Ao tomar conhecimento do texto, a delegação do Brasil anunciou ao Grupo dos 77 sua discordância com a redação incompleta. Como, porém, ele já havia sido acordado previamente, a delegação comprometeu-se a não objetá-lo nas discussões com os demais participantes da Cúpula, desde que estes o aceitassem tal como estava.

Nas discussões do grupo de trabalho pertinente, o texto foi impugnado pela União Européia, tanto por sua extemporaneidade, como pela linguagem restritiva inaceitável. Após novo adiamento das discussões, a União Européia dispôs-se a relevar a extemporaneidade da proposta, desde que passasse a incluir menção aos direitos humanos. Face às resistências ainda demonstradas pelos porta-vozes do Grupo dos 77, a delegação brasileira cumpriu o que anunciara: comunicou ao grupo de trabalho reunido sobre o assunto que, sem a menção imprescindível aos direitos humanos, o parágrafo não mais poderia ser encarado como proposta coletiva do Grupo, por não contar com seu apoio. Em função dessa intervenção decisiva, o chapeau dos compromissos de Copenhague (parágrafo 28 da Declaração) passou a ler, em consonância com o texto do Cairo: "Nossa campanha mundial em prol do desenvolvimento social e as recomendações de medidas descritas no Programa de Ação são feitas com espírito de consenso e cooperação internacional, de conformidade com os Propósitos e Princípios da Carta das Nações Unidas, reconhecendo que a formulação e a implementação das estratégias, políticas, programas e ações em favor do desenvolvimento social são de responsabilidade de cada país e devem levar em conta a diversidade econômica, ambiental e social das respectivas condições, com pleno respeito aos diversos valores religiosos e éticos, contextos culturais e convicções filosóficas de sua população, e em conformidade com todos os direitos humanos e liberdades fundamentais. Nesse sentido a cooperação internacional é essencial para a plena implementação dos programas e ações de desenvolvimento social”. ${ }^{26}$ 
Se a supervalorização das identidades tradicionais é tendência que se generaliza nestes tempos "pós-modernos", seja como reação ao atomismo individualista das sociedades desenvolvidas, seja como resistência "pré-moderna" ao "imperialismo" num mundo globalizado pela economia e pelas comunicações, aos países de tradição liberal universalista, desenvolvidos ou em desenvolvimento, não cabe assimilar o particularismo cultural não-qualificado como sua posição. A resistência do Sul deve concentrar-se em outras áreas, diretamente atinentes à situação de inferioridade econômica e tecnológica em que se encontra. Aceitar passivamente a manipulação do Grupo dos 77 por governos integristas de valores alheios, mais do que um desserviço à legitimidade do que se pretende defender no campo econômico, pode até constituir um estímulo a retaliações, comerciais e de outra ordem, contrárias ao interesse próprio. Tende, ainda, a inserir falsamente os Estados democráticos em desenvolvimento, que prezam a liberdade política e os direitos individuais de sua população, no bloco cultural que lhes seria antagônico, caso o suposto “conflito de civilizações” viesse a tornar-se realmente o novo paradigma do mundo contemporâneo visualizado por Samuel Huntington.

A Declaração e o Programa de Ação de Copenhague não chegaram, tal como aprovadas, a reverter posições consensuais das Conferências de Viena e do Cairo em matéria de direitos humanos. Os riscos foram, porém, ponderáveis. E a reiteração de reservas a trechos dos documentos a eles atinentes pressagiavam as resistências autoritárias e fundamentalistas que se iriam repetir na IV Conferência Mundial sobre a Mulher, em Pequim, em setembro de 1995, e na II Conferência Internacional sobre Assentamentos Humanos, Habitat II, em Istambul, em junho de 1996. Evidenciavam, ainda, de forma clara, a desunião do Grupo dos 77 em matéria de valores. Natural num conjunto de Estados profundamente heterogêneo, essa desunião não precisaria aflorar de maneira tão constrangedora se o Grupo se ativesse a buscar manter a unidade em questões econômicas, ao invés de extrapolar os objetivos para os quais foi criado.

\section{Conseqüências da Cúpula}

Como ocorre com as decisões acordadas em qualquer reunião multilateral normativa, da ONU ou fora dela, ninguém espera que os documentos da Cúpula deCopenhague sejam traduzidos em efeitos imediatos. Comexceção das resoluções do Conselho de Segurança adotadas ao abrigo do Capítulo VII da Carta das Nações Unidas, que prevêem algum tipo de sanção compulsória a transgressores da paz ou criam forças internacionais para determinadas situações de conflito, 
todos esses encontros constituem esforços dialógicos para a definição de padrões e diretrizes destinados ao aperfeiçoamento da convivência humana. Geralmente a esfera regulada é a internacional. No caso específico da agenda social da ONU, busca-se orientar tanto as relações entre as nações, quanto o ordenamento interno de cada uma. Impregnados de conteúdo ético, todos os resultados do presente ciclo de conferências somente poderão ter efeitos concretos em prazo não-previsível. Seu objetivo mais imediato não ultrapassa o da mobilização de consciências e, se possível, de iniciativas que possam levar, no futuro, à concretização de suas propostas.

Denominada pela imprensa “Cúpula da Pobreza”, o encontro de dirigentes políticos em Copenhague congregou o maior número de Chefes de Estado e de Governo da história, todos os quais, pessoalmente ou por representação, subscreveram, com a participação no evento, os compromissos erecomendações dele emanados. Reunião de tais dimensões e nível não poderia deixar de ter, por si só, importante valor simbólico. Mas algo mais concreto dela emergiu: os governados passaram a contar com uma declaração de compromissos governamentais e um programa de ação para sua implementação, com base nos quais podem legitimamente cobrar dos governantes o cumprimento de suas promessas neles registradas. Tendo em conta que a preparação de cada país ou pelo menos dos países democráticos - para o encontro, conforme as recomendações das Nações Unidas na matéria, deveria ter envolvido não apenas os respectivos governos, mas também os segmentos interessados da sociedade civil, é de prever que tais segmentos, ativos no processo preparatório e na própria conferência, não deixarão no ostracismo as promessas e recomendações de Copenhague.

No caso do Brasil, o processo preparatório seguiu estritamente as recomendações das Nações Unidas. Orelatório nacional, elaborado por consultora não-governamental a partir de subsídios fornecidos por seminários convocados sobre os três temas principais da Cúpula - pobreza, desemprego e integração social-e aprovado por consenso pelos membros do Comitê Nacional estabelecido pelo Governo para coordenar a preparação brasileira, chegou a surpreender por sua franqueza. ${ }^{27}$ Exatamente por não pintar com tons dourados o quadro reconhecidamente difícil da situação social do país, ele oferece importante subsídio ao diagnóstico dos problemas nacionais, a serem abordados de maneira democrática e participativa pelo Governo e pela sociedade, conforme recomenda a agenda social das Nações Unidas. Essa interação Governo-sociedade que caracterizou o processo preparatório e se manteve durante a realização do evento dentro da delegação nacional, de composição mista, além de assegurar 
legitimidade às posições do país, conferiu-lhes a solidez necessária atémesmo para discordar do Grupo dos 77 quando tal se fez imperativo. ${ }^{28}$

A experiência brasileira na Cúpula de Copenhague - experiência que, na verdade, apenas consolidou o que já vinha sendo feito nas demais conferências da década, particularmente na de População e Desenvolvimento do Cairo evidencia que, pelo menos na esfera da participação, o Brasil se encontra aparelhado para os desafios com que se defronta.

Participação e parceria têm sido a tônica das Conferências da ONU dos anos 90, em claro distanciamento do estatismo que prevalecera nas décadas anteriores. Conforme assinalaram os Chefes de Estado e de Governo na Declaração de Copenhague: "Nosso desafio é o de estabelecer um modelo de desenvolvimento social centrado nas pessoas, que nos guie, agora e no futuro, para construir uma cultura de cooperação e parceria e para responder às necessidades imediatas daqueles mais afetados pela privação humana.”29

É importante sublinhar, porém, que parceria não significa transferência deresponsabilidades.

O Estado, neste fim de século, não mais se confunde com a sociedade, sequer na esfera das relações internacionais. Tampouco se apresenta como o instrumento apto e suficiente à realização do progresso e da liberdade idealizado pela Ilustração. Hoje, mais do que nas décadas passadas, as ações da sociedade civil se afirmam, nacional einternacionalmente, como fator imprescindível à luta contra a marginalização, em prol da coesão social. Daí a importância crescente atribuída pelas Nações Unidas à participação dos órgãos não-governamentais nos debates e na implementação de decisões de suas conferências sobre temas globais. Mas as ações do Estado e da sociedade civil não são mutuamente excludentes. O conceito de participação não exime o Estado de suas responsabilidades. A ele incumbe não somente o monopólio legítimo da força ou a tarefa de gerir com eficiência a economia nacional. Incumbem-lhe igualmente funções distributivas intransferíveis, exercitáveis, desde que para tanto haja determinação, nas competências normativa, administrativa, fiscal, policial, judicial e todas as demais que lhe são inerentes. Se a razão instrumental nas mãos do Estado comprovou-se insuficiente para a promoção do progresso humano, nada indica que o mercado por si só ou as Organizações não-governamentais isoladamente possam garanti-lo de forma abrangente. É imprescindível, portanto, que as políticas públicas governamentais sejam harmonizadas com as ações da sociedade civil e com o exercício da cidadania. Essa mensagem fica clara nos documentos da Cúpula Mundial sobre o Desenvolvimento Social. 
A falta de inovações em matéria de cooperação econômica internacional do encontro de Copenhague, difícil de obter em qualquer circunstância e mais previsível ainda num período de indiferentismo neoliberal dominante, pode ser, por sua vez-e paradoxalmente-útil aos governos de países em desenvolvimento. Com ela se demonstra que o bem-estar de suas populações não pode ficar passivamente dependente da benemerência alheia. Sem vigorosos esforços redistributivos das lideranças políticas e econômicas domésticas - e, malgrado os efeitos negativos da globalização, todos podem sempre fazer algo mais -, não há como produzir nos países mais ricos ações ou sentimentos de solidariedade (salvo alguns gestos simbólicos, algumas vezes contraproducentes, para com casos extremos de miséria generalizada e anomia, como recentemente verificados no continente africano). Afinal o conceito de "boa governança” permanece atual, menos arrogante e não mais exclusivo na crítica ao Terceiro Mundo. Se a sociedade civil, o mercado ou os governos sozinhos não têm a possibilidade de resolver os problemas existentes no próprio Norte, tampouco o resolverão simples postulações diplomáticas do Sul, bi ou multilaterais, para a obtenção de recursos externos, quando desacompanhadas de iniciativas nacionais conseqüentes para promover melhorias nas condições de vida dos segmentos marginalizados das respectivas sociedades.

As frustrações propiciadas pela Cúpula não devem dar lugar ao negativismo derrotista, nem a atitudes pretensiosamente "pós-modernas", denegadoras dos valores da Ilustração. Apesar de algumas falhas substantivas e irracionais dos documentos, a política e a filosofia moral que permeiam a rationale e as recomendações de Copenhague são, na interpretação da própria ONU, “fundamentalmente enraizadas na tradição ocidental da Ilustração”. ${ }^{30} \mathrm{O}$ progresso, de indivíduos e comunidades e do mundo como um todo, é considerado possível e essencialmente definido em termos da satisfação de necessidades e das relações pacíficas entre indivíduos e grupos. Há, por outro lado, também, uma crítica à concepção tradicional do desenvolvimento e do progresso: “Ademais da noção de sustentabilidade, que pode ser encarada como produto normal do bom senso e da razão, a Declaração de Copenhague alude a um número de limites que deveriam dar forma ao impulso prometéico pelo crescimento e pelo bem-estar material. Há o reconhecimento de que a pessoa humana tem muitas dimensões e aspirações, e que as necessidades espirituais são tão fundamentais à natureza humana quanto o desejo de uma vida mais confortável”. ${ }^{31}$

Longe de representar a superação do projeto da modernidade, tais atualizações procuram, ao contrário, adaptá-lo a uma realidade mais humana e menos arbitrária do que a razão abstrata e individualista dos filósofos do Iluminismo. 
No cômputo geral, o evento foi positivo. Cooperação e participação, mas, sobretudo, determinação comprovada em esforços concretos de todos, dentro de um espírito verdadeiramente humanista, inter-subjetivo, que valoriza o individual sem negligenciar o comunitário, representam a mensagem subjacente aos compromissos assumidos em Copenhague. É com base nela, e numa razão não meramente instrumental, que o desenvolvimento social se afirma, em sua nova conceituação, na agenda internacional deste fim de século como um dos mais importantes temas globais, a que se vinculam a paz e a possibilidade de progresso no próximo milênio. É ele que legitima qualquer projeto de desenvolvimento econômico.

Maio de 1997

\section{Notas}

1 Documento das Nações Unidas A/CONF.166/9, p.5. Todas as citações dos documentos de Copenhague no presente texto são traduções feitas a partir do original em inglês. Versão não-oficial em português, feita no Brasil pelo Centro de Estudos da Fundação Konrad Adenauer, pode ser encontrada na publicação Relatório da ONU sobre a Cúpula Mundial para o Desenvolvimento Social, série Traduções, Ano 1995, n. 8, São Paulo: Konrad Adenauer Stiftung.

2 Sobre o "direito de ingerência” v. J. A. Lindgren Alves, Os direitos humanos como tema global, São Paulo: Perspectiva, e Brasília: Fundação Alexandre de Gusmão, 1994, pp.38-39.

3 United Nations, Resolutions and decisions adopted by the General Assembly during the first part of its Forty-Seventh Session, Press Release GA/8470, 1 February 1993, pp. 298-301.

4 United Nations, Social Policy \& Social Progress, Special Issue on the Social Summit, Nova York, 1966, pp. 5-6.

5 Id., ibid., pp. 14-19.

$6 \quad$ Id., ibid, p. 3.

7 Documento das Nações Unidas A/CONF.166/9, p. 5. Os grifos não existem no original.

8 Intervenção no Seminário “Cúpula Mundial para o Desenvolvimento Social: avaliação e implicações futuras para as políticas sociais no Brasil e na Alemanha”, in O difícil caminho para a justiça social, São Paulo: Konrad Adenauer Stiftung, Coleção Debates, Ano 1995, n. 7, p. 36.

9 A redação do sexto compromisso é das mais confusas, em todas as versões da Declaração, em decorrência dos múltiplos aportes das mais variadas procedências. 
A parte entre aspas aqui indicada é reprodução literal do texto, importante na medida em que recorda os três objetivos fundamentais de toda a Conferência: a erradicação da pobreza, a expansão do emprego produtivo e a integração social dos marginalizados (v. supra, p. 4).

10 Documento das Nações Unidas A/CONF.166/9, pp. 11-26.

11 United Nations Department of Public Information, Programme Update, 31 March 1995.

12 Documento das Nações Unidas A/CONF.199/9, p. 11

13 Ibid., passim.

14 V.supra, p. 5.

15 “Lofty commitments and empty pockets” - expressão largamente empregada nos jornais de ONGs distribuídos durante e depois da realização do evento, logo após haver-se chegado a acordo, no Comitê Plenário, sobre o texto dos documentos a serem adotados.

16 Documento das Nações Unidas A/CONF.166/9, p. 83. Desde 1960, pela Resolução 1522, a Assembléia Geral das Nações Unidas já havia fixado em 1\% da Renda Nacional dos países desenvolvidos o montante básico de recursos a serem alocados à assistência internacional. Em 1968, a segunda UNCTAD modificava essa meta para 1\% do PNB. Em 1970, a primeira Estratégia das Nações Unidas para o Desenvolvimento estabelecia um prazo curto para a realização desse objetivo, reduzindo-o, porém, para o quantitativo mais modesto de $0,7 \%$ do PNB - tal como agora reiterado pela Cúpula de Copenhague. No entanto, como é sabido e comprovado pelos estudos da OCDE, apenas os países escandinavos haviam atingido - e ultrapassado - tal meta no início dos anos 90. Em 1992, as alocações à assistência internacional da França situavamse em 0,63\%, as do Japão em 0,30\% e as dos Estados Unidos em 0,20\% (v. Monique Chemillier-Gendreau, Humanités et souverainetés - essai sur la fonction du droit international, Paris: La Découverte, 1995, p. 257)

17 Documento das Nações Unidas A/CONF.166/9, p. 8.

18 Peter Townsend, "Will the rich countries pay more attention to problems in their own backyards?”, in United Nations, Social Policy \& Social Progress, p. 3.

19 Ignacy Sachs, "Em busca de novas estratégias de desenvolvimento”, Estudos Avançados, Vol. 9, n 25, set./dez. 1995, São Paulo, USP, pp. 30 e 37.

20 Relatório do PNUD sobre o Desenvolvimento Humano de 1996, p. 2.

21 Ver sobre o assunto J.A.Lindgren Alves, “A Conferência do Cairo sobre População e Desenvolvimento e o paradigma de Huntington”, Margem, n. 4, Faculdade de Ciências Sociais da PUC, São Paulo, 1995, p. 35-54, e Revista Brasileira de Estudos Populacionais, Vol.12, ${ }^{\text {os }}$ 1-2, jan./dez. 1995, Campinas, ABEP.

22 Apud. João Almino, Naturezas mortas - a filosofia política do ecologismo, Brasília: FUNAG/IPRI, 1993, p. 74.

23 O Brasil é membro do Grupo dos 77 desde sua formação na década de 60. Do Movimento Não-Alinhado nunca chegou a fazer parte, embora participe de seus encontros na qualidade de observador. 
24 A não ser que o conjunto de delegações entendesse unanimemente que algum assunto de importância capital havia sido omitido, por inadvertência ou falta de tempo, no processo preparatório - como foi o caso do compromisso sobre educação, negociado em Copenhague sob coordenação do Brasil, e consubstanciado no Sexto Compromisso da Declaração.

25 Documento das Nações Unidas A/CONF.171/13, p. 12.

26 Documento das Nações Unidas A/CONF.166/9, p. 11 (meus grifos).

27 O Relatório Nacional Brasileiro à Cúpula Mundial sobre o Desenvolvimento Social, encaminhado à ONU dentro do processo preparatório nacional para o evento, foi publicado pelo Ministério das Relações Exteriores, em 1995, e objeto de ampla divulgação nos meios interessados. A relatora geral, escolhida consensualmente pelo Comitê Nacional estabelecido por Decreto presidencial de 3 de fevereiro de 1994, foi a Professora Amélia Cohn, Presidente do Centro de Estudos de Cultura Contemporânea - CEDEC. Integraram o Comitê Nacional representantes dos seguintes órgãos: Ministério das Relações Exteriores, Ministério da Justiça, Ministério da Educação e do Desporto, Ministério do Trabalho, Ministério da Previdência Social, Ministério da Saúde, Ministério do Bem-Estar Social, Secretaria de Planejamento, Orçamento e Coordenação da Presidência da República, Secretaria de Assuntos Estratégicos da Presidência da República. A Agência Brasileira de Cooperação funcionou como núcleo de articulação técnica. Todas as reuniões do Comitê Nacional contaram com a participação ativa de Organizações não-governamentais, associações sindicais e outras entidades não-oficiais na qualidade de observadores. Esse intercâmbio governo-sociedade, já presente nas deliberações do Comitê Nacional, foi expandido e aprofundado sobretudo nos seminários realizados dentro do processo preparatório do Relatório Nacional.

28 A delegação brasileira foi chefiada pelo Ministro da Educação Paulo Renato Costa Souza, que representou o Presidente Fernando Henrique Cardoso na Cúpula propriamente dita, nos dias 11 e 12 de março. A coordenação dos delegados e observadores nacionais nas negociações foi realizada pelo Embaixador Luiz Paulo Lindenberg Sette, Chefe alterno da delegação, que já atuara no processo preparatório internacional para o evento como representante pessoal do Presidente da República. A delegação contou com participantes de todos os órgãos oficiais que compunham o Comitê Nacional, com quatro observadores parlamentares e com a assessoria de 14 representantes das entidades da sociedade civil que haviam, desde o início, atuado no processo preparatório brasileiro. Acompanharam também os trabalhos representantes da Prefeitura do Rio de Janeiro e da Universidade de Brasília.

29 Documento das Nações Unidas A/CONF. 166/9, p. 9.

30 Nações Unidas, Social Policy \& Social Progress, pp. 7-8.

31 Idem, ibid. 


\section{Resumo}

Este artigo analisa a Cúpula Mundial sobre Desenvolvimento Social, realizada em Copenhague, em 1995, onde foram debatidos os problemas e as possíveis soluções para o desenvolvimento social e do bem-estar humano de todos.

\section{Abstract}

This article analyses the World Summit on Social Development, that was held in Copenhague, in 1995, when was debated the problems and possible solutions to the social development and the human welfare of mankind.

Palavras chaves: Desenvolvimento social. Nações Unidas. Key-words: Social development. United Nations. 